\title{
On evidence and evidence-based medicine: Lessons from the philosophy of science
}

\author{
Maya J. Goldenberg \\ Michigan State University, East Lansing, Mich., USA \\ Available online 27 December 2005
}

\begin{abstract}
The evidence-based medicine (EBM) movement is touted as a new paradigm in medical education and practice, a description that carries with it an enthusiasm for science that has not been seen since logical positivism flourished (circa 1920-1950). At the same time, the term "evidence-based medicine" has a ring of obviousness to it, as few physicians, one suspects, would claim that they do not attempt to base their clinical decision-making on available evidence. However, the apparent obviousness of EBM can and should be challenged on the grounds of how 'evidence' has been problematised in the philosophy of science. EBM enthusiasm, it follows, ought to be tempered.

The post-positivist, feminist, and phenomenological philosophies of science that are examined in this paper contest the seemingly unproblematic nature of evidence that underlies EBM by emphasizing different features of the social nature of science. The appeal to the authority of evidence that characterizes evidence-based practices does not increase objectivity but rather obscures the subjective elements that inescapably enter all forms of human inquiry. The seeming common sense of EBM only occurs because of its assumed removal from the social context of medical practice. In the current age where the institutional power of medicine is suspect, a model that represents biomedicine as politically disinterested or merely scientific should give pause.
\end{abstract}

(C) 2005 Elsevier Ltd. All rights reserved.

Keywords: Evidence; Evidence-based medicine; Philosophy of science; Positivism; Feminist epistemology; Phenomenology

\section{Introduction}

To have evidence is to have some conceptual warrant for belief or action (Goodman 2003, p. 2), and it is the practice of basing all beliefs and practices strictly on evidence that allegedly separates science from other activities (Husserl, 1982; Kuhn, 1996). The evidence-based medicine (EBM) movement purports to eschew unsystematic and "intuitive" methods of individual clinical practice in favour of a more scientifically rigorous approach.

E-mail address: golden11@msu.edu.
This rigour is achieved through methodological clinical decision-making based on examination of evidence derived from the latest clinical research. Evidence as accumulated data has been made widely and easily available to clinicians and educators by evolving information technologies, and EBM aficionados, such as those found in the Cochrane Collaboration (Grimshaw, 2004) and on the editorial boards of various evidence-based practice journals, describe the movement as a new paradigm in medical education and practice, a description that carries with it a science enthusiasm that has not been seen since the days of positivism. 
The term "evidence-based medicine", and its standard definition as "the conscientious, explicit, and judicious use of current best evidence in making decisions about the care of individual patients" (Sackett, Rosenberg, Gray, Haynes, \& Richardson, 1996, p. 71), has a ring of obviousness to it which makes it difficult to argue against. Few doctors, one suspects, would be willing to assert that they do not attempt to base their clinical decision-making on available evidence. ${ }^{1}$ However, the apparent obviousness of EBM can and should be challenged on the grounds of how 'evidence' has been problematised in the philosophy of science. In this paper, I argue that evidence-based practices maintain an antiquated understanding of evidence as "facts" about the world in the assumption that scientific beliefs stand or fall in light of the evidence. This understanding of evidence is explicitly positivist, and such a picture of science has been seriously undermined by post-positive philosophies of science. EBM's ability to guide healthcare decision-making by appealing to "the evidence" as the bottom line is attractive to many because it proposes to rationalise this complex social process. Yet it does so through the positivistic elimination of culture, contexts, and the subjects of knowledge production from consideration, a move that permits the use of evidence as a political instrument where power interests can be obscured by seemingly neutral technical resolve.

Logical positivism is a philosophical system that recognises only scientifically verifiable propositions as meaningful. This school of thought originated in Vienna in the 1920s by a group of philosophers and scientists concerned with the philosophy of formal and physical science. However, it was their attitude toward science and its relationship to philosophy that defines the "Vienna Circle". Because the Circle rejected the possibility of justifying knowledge claims that were "beyond" the scope of science, they dismissed metaphysics and many of the claims made in theology and ethics as nonsensical (or unverifiable). Emigration by many of the Circle's members to Britain and the United States during the early war years led to the strong influence of logical positivism on Anglo-American analytic philosophy. The "post-positive turn" in the philosophy of science refers to the critical examinations of scientific thought and practice that originated in

\footnotetext{
${ }^{1}$ This has led some critics to suggest that there is nothing new about EBM (Sackett et al., 1996, p. 71).
}

the second half of the 20th century by such historically oriented philosophers as Thomas Kuhn, Norwood Hanson, and Paul Feyerabend. Their historical analyses of scientific change and progress undermined the positivist-empiricist endorsement of the claims of science to provide a value-free understanding of the natural world. Their examination of the relationship between science and values (and the denial of their possible or even preferable separation) has been enriched by the insights of feminist epistemologies of science and phenomenological investigations. Feminist epistemologists have exposed the political stakes in knowledge production by demonstrating the androcentric assumptions underlying conventional understandings of scientific thought and practice, while phenomenologists have questioned the goals and methods of scientific medicine through examination of the patient's lived experience of illness and disease. In this paper, I take the lessons learned from post-positivist, feminist, and phenomenological epistemologies of science's critiques of the presumed "self-apparentness" of evidence and consider their implications for EBM.

\section{Evidence and evidence-based medicine}

The popular histories of science recount scientific progress as having been motivated by the evidencebased practices of innovative scientists. Rejecting the dogma and superstition that pervaded their historical moment, these innovators let the evidence, as gathered through unbiased and careful experimentation, dictate their scientific practices, beliefs, and theories (Harding, 1986; Kuhn, 1996). Thus science purports to be a democratic enterprise insofar as the beliefs of the Church, accomplished colleagues, or department chairs are subject to the same critical inquiry as lay beliefs.

The EBM movement centres around five linked ideas: first, clinical decisions should be based on the best available scientific evidence; second, the clinical problem, and not the habits or protocols, should determine the type of evidence to be sought; third, identifying the best evidence means using epidemiological and biostatistical ways of thinking; fourth, conclusions derived from identifying and critically appraising evidence are useful only if put into action in managing patients or making health care decisions; finally, performance should be constantly evaluated (Davidoff, Haynes, Sackett, \& Smith, 1995, p. 1085). Evidence-based medical practice 
purports to achieve these goals by enlisting numerous techniques for the management, evaluation, and application of clinical data into medical practice. Its hallmark is the hierarchy of evidence that consistently places the evidence derived from randomised controlled clinical trials on top (Sackett et al., 1996, p. 72). The synthesis of large amounts of clinical trial data into manageable "clinical summaries" or "meta-analyses" by the hardworking volunteers at the Cochrane Collaboration and other institutional affiliates and the proliferation of this information via EBM journals and electronic databases are supposed to revolutionise medical practice and offer objective and politically transparent criteria for funding decisions at the policy level.

"Evidence-based" is typically read in medicine and other life and social sciences as the empirically adequate standard of reasonable practice and a means for increasing certainty. Evidence-based practices are therefore enormously appealing in the age of moral pluralism; rather than relying on explicit values that are likely not shared by all, "the evidence" is proposed to adjudicate between competing claims. (Goldenberg, 2005). However, the notion that any claim (including scientific beliefs) can stand or fall in light of the evidence assumes a "givenness" of evidence as "facts" about the world. Positivistic empiricists have regarded evidence in this way: any bias that enters scientific inquiry in the context of discovery is eradicated in the purifying process of the context of justification. The evidence left standing after scientific inquiry is assumed to be "facts" about the world and therefore warrants the title scientific evidence.

EBM promotes such a scientific conception of evidence in its endorsement of evidence derived from systematic and methodologically rigorous clinical research and maligning the use of intuition, unsystematic clinical experience, patient and professional values, and pathophysiologic rationale (Buetow \& Keneally, 2000; Guyatt, Cairns, Churchill et al., 1992). This preference has prompted critics to detail other sources of evidence that enter into clinical decision-making (Buetow, 2002; Buetow \& Keneally, 2000; Upshur, VanDenKerkhof, \& Goel, 2001) and to defend the unsystematic intuitions and expertise that arise from clinical experience as epistemically significant and indispensable to clinical decision-making (Tanenbaum, 1993). Yet even before we consider the complex nature of clinical decision-making, we can question the very tenability of the conception of evidence being assumed in evidence-based practice. This paper draws on major lines of thinking in the philosophy of science over the past half century to question the "evidence base" of EBM.

\section{Post-positivist philosophy of science}

Much of the philosophy of science over the last half century has been preoccupied with challenging the positivist picture of scientific methodology on two grounds. In the first, Hanson (1958), Kuhn (1970, 1996) and Feyerabend (1978) have claimed that observation is theory-laden; that is, our observations are "coloured" by our background beliefs and assumptions (and therefore can never be, even under the most ideal circumstances or controlled experimental settings, the unmitigated perception of the nature of things). In the second, Duhem (1982) and Quine (1960) have argued that theories are underdetermined by data. In other words, our theory choices are never determined exclusively by "the evidence".

The first claim is damaging (if not devastating) to the positivist empiricist picture because the principles of empiricism are tendered against the background presupposition that one's perceptions are unaffected by the beliefs one has and by the assumptions one makes about the objects that one is observing. These observations are supposed to provide a maximally certain and conceptually unrevisable foundation of empirical knowledge, a foundation that supplies the basic premises of all our reasoning and without which there would not even be any probable knowledge. Empiricist epistemology, from Hume's $(1977,2000)$ 18th century configurations onward, seems to rest on the assumption that there is an absolutely stable and invariant correspondence between perceptions and the stimuli which produce them. The critics mentioned above object that observations are not "givens" or "data", but are always the product of interpretation (in light of our background assumptions). The idea of unambiguous objects of perception is a myth, as 'multistable' images (such as Wittgenstein's duck/rabbit and the popular old lady/young lady image) aptly demonstrate. This exercise in gestalt psychology suggests that what someone perceives is not independent of one's beliefs and expectations.

The charge that theories are underdetermined by data-commonly referred to as the "Duhem-Quine thesis" in the philosophy of science-concerns the 
claim that any given body of evidence may support numerous, even contradicting, theories. The charge once again undermines empirical science's selfunderstanding as an objective enterprise that progresses (i.e., accepts, refines, or rejects scientific theories) in light of how theories stand up to empirical evidence. Since scientific theories are deductively underdetermined by the data, scientists must adopt extraempirical criteria for what counts as a good theory when deciding to accept one theory in preference over its empirically adequate rivals. This "extraempirical criteria" is subject to the whims, preferences, biases, and social agendas of the researching scientists, and not the rigour of evidenced-based adjudication.

While the "theory ladenness" objection challenges the stability of observations themselves, the "underdetermination" thesis undermines the stability of evidential relations. Both accounts have seemed to permit the unrestrained expression of scientists' subjective preferences in the content of science. If observation is theory-laden, then it cannot serve as an independent constraint on theories, thus permitting subjective elements to constrain theory choice. Similarly, if observations acquire evidential relevance only in the context of a set of assumptions, a relevance that changes with a suitable change in assumptions, then it is not clear what protects theory choice from subjective elements hidden in one's background assumptions. Although empirical adequacy serves as a constraint on theory acceptance, it is not sufficient to pick out one theory from all contenders as the true theory regarding a domain of the natural world.

\section{Post-positive implications for EBM}

A 1995 publication in The Lancet documented the disagreement among members of a research team regarding the interpretation of their trial results for streptokinase treatment for acute ischemic stroke (Horton, 1995). Upon "agreeing to disagree", the team presented two views (see Candelise, Aritzu, Ciccone, Ricci, \& Warlaw, 1995; Tognoni \& Roncaglioni, 1995). No one position was seen to be wrong at least insofar as both sides appeared to be supported by the clinical data (Horton, 1995).

Even within the confines of strictly evidence-based practice, empirical evidence undergoes numerous subjective interpretations. There is room for dispute regarding the design of a study on the grounds of measurement error, contaminated solution, mal- functioned equipment, poor design, or bias, and there are no predetermined rules for the statistical interpretation of the results of a test (Shahar, 1997). The highly prized meta-analysis provides a further level of interpretation, one that is notably "high impact" insofar as it carries the institutional brand "evidence-based medicine" and because individual practitioners who rely on these summaries for evidence-based decision-making are no longer critically reading the trial data. Finally, the practitioner must apply one more layer of interpretation in her application of trial results to a specific patient. The formal methods promoted by EBM to replace so-called "traditional" medicine's overreliance on intuition, habits, and unsystematic clinical experience (Guyatt et al., 1992) appear to repeat the misplaced effort to separate science from values.

\section{Feminist epistemologies of science}

Feminist philosophers endorse the post-positivistic conclusions derived from analyses of the relations between observation, evidence, and theory and have taken the critique of empiricist epistemology further to challenge empiricism's "silent partner": the theory of the unconditioned subject. This unbiased observer is argued in feminist thought to be the necessary companion to empiricist epistemology, and reflection on this subject's unusual and implausible ontology reveals further difficulties with positivist thought. Positivism, therefore, not only errs in holding sensory observation in ideal observation conditions as the privileged source of knowledge, but also inappropriately attaches a dubious theory of epistemic agency in which knowers are detached and neutral spectators separate from the objects of knowledge. Positivist empiricism does not, in fact, yield neutral and universally valid conceptions of knowledge. Instead, knowledge is indelibly shaped by its creators and attests to the specificities of their epistemic locations. Indeed, it is because subjects are irrelevant to the knowledge claims that the latter appear to be verifiable by appeals to the evidence (Code, 1993, p. 17).

Notions of evidence and theories of epistemic agency are, therefore, closely related. Haraway (1996) argues that the notion of "matters of fact" depends on many kinds of transparencies in the grand narratives of the experimental way of life. The "modest witness", the protagonist of the dramas of 
the Scientific Revolution who testifies without prejudice to new facts, had to be constructed in sufficiently detached and abstracted terms to make plausible the unusual situation where his experiences could somehow represent everyone's and no-one-inparticular's experiences. Notions of evidence as "self-appearing" similarly rely on such a knower (Nelson, 1993a).

Feminist epistemologies of science have demonstrated that the ideals of the autonomous knowerthe dislocated, disinterested observer-and the epistemologies they inform are the artefacts of a small, privileged group of educated and prosperous white men. Their material circumstances allow them to believe that they are autonomous individuals without specific locations (i.e., gendered or raced) even in their positions of privilege. ${ }^{2}$ Haraway's postulation of such a "modest man", whose narratives mirror reality, requires invisibility, such that "such a man must inhabit the space perceived by its inhabitants to be the "culture of no-culture" (1996, p. 429).

In this culture, the inhabitant's contingencies can be established with all of the authority, but none of the considerable problems, of transcendental truth. His modesty is of a specifically modern, professional, European, masculine and scientific form (and is therefore very different from the virtue typically attributed to women), and it imbues him with a disguised epistemological and social power concealed by modernist ideals of "rationality", "objectivity", and "value-neutrality". His modesty guarantees his legitimacy as an "authorised ventriloquist for the object world, adding nothing from his mere opinions, from his biasing embodiment. And so he is endowed with the remarkable power to establish the facts. He bears witness" (Haraway, 1996, p. 429).

Underlying the orthodox account of scientific investigation and justification is a presumed universality of experience (or at least the potential for such universality through the refined abilities of the modest witness), which presumes, in turn, both a view of evidence and a view of knowers, where individuals have unmediated or unfiltered access to a reality that itself admits of only one system-

\footnotetext{
${ }^{2}$ Feminist psychologists have argued that affluent white boys are nurtured to embody the psychosocial characteristics needed for detached and objective knowledge seeking, deliberation, and work. For example, see Keller (1985) and Bordo (1987). It should therefore be no surprise that they can come to see themselves as disembodied rational beings.
}

atisation (Nelson, 1993a, p. 131). It is only by positing this framework of a shared reality experientially accessible to all sentient beings that anybody (or everybody) can discover, observe, or witness truths about the world. While one's faith in such universality might be partly underwritten by similarities in sense organs, it also requires that there is a unique and true theory of nature and that our sense organs are sufficiently refined to discover it and discriminate it from possible alternatives (Nelson, 1993a, p. 132). Experience alone, however, does not warrant the assumption that only one system could organise the world or that the world is of a determinate nature, specifiable in categories that our sense organs will lead us to discover. There is nothing in our experience to rule out the possibility of a future theory that is commensurate with all of our experiences to date but incompatible with the current theory. There is also nothing in our experience or in our current knowledge about our sense organs to warrant the inference that they are able to discriminate a "best" theory of nature (if, indeed, there is such a thing) from multiple candidates.

Feminist epistemologists are particularly resistant to the notion of shared experience that supports orthodox empiricism because feminist investigations into the lives of women reveal great diversity of experiences, many of which are distinctly gendered, raced, classed, or mediated by numerous other social stratifications. For orthodox empiricists (including positivists, who apply radical empiricist epistemology to science) historical, gendered, and locational differences between and among knowers reduce to bias or aberration and should be discounted in formal justification procedures. Feminists object that such reductions exclude and even harm women, as the so-called universals that are thought to underlie the social context (and serve as the foundation of scientific knowledge) are distinctly androcentric. This claim has been illustrated by numerous documentations of gender bias in the natural and biological sciences (for example, see Fausto-Sterling, 1989, 1992; Haraway, 1989, 1991; Hubbard \& Lowe, 1979; Keller, 1985). For all of its alleged experiential grounding, the experience with which empiricism works is an abstraction in which cognitive specificities are homogenised under one dominant conception of what counts as knowledge and of who qualifies as a knower. In practice, those conceptions mirror and replicate the experiences that their (usually white, male, prosperous, and 
educated) creators are positioned to regard as exemplary (Code, 1991).

The inexactness of the term "experience" seems to allow it to resonate in many ways, to function as a universally understood category, and to create a sense of consensus by attributing to it an assumed stable and shared meaning (Scott, 1991, p. 782). Through its assumption as a foundational concept in empiricist epistemology, experience is protected from different meanings and relativisms, and therefore establishes the possibility for objective knowledge (Scott, 1991, p. 785). This move effectively removes subjects from critical scrutiny as active producers of knowledge, and it is this insistence of separation of meaning and experience that is crucial. Epistemology constructs "truth" on the foundation of the speaker's irrelevance (Scott, 1991, p. 785).

That speaker is, of course, the modest witness. It has already been discussed how he bears witness in his unbiased accounts of the world. His modesty authorises him to do so. His subjectivity, therefore, is his objectivity. Lorraine Code has argued that "objectivity" is "a generalization from the subjectivity of quite a small group" (1993, p. 22). However, this group "has the power, security, and prestige to...generalise its experiences and normative ideals across the social order thus producing a group of like minded practitioners ('we') and dismissing 'others' as deviant and aberrant ('they')" (Code 1993, p. 22). Within the privileged "culture of no culture", the witness's narratives "lose all trace of their history as stories, as products of partisan projects, as contestable representations, or as constructed documents in their potent capacity to define the facts" (Haraway 1996, p. 429). The evidence of experience is therefore called into question.

For positivist epistemologies, of which medicine retains its residue, sensory observation and experience in ideal conditions is a privileged source of knowledge offering the best promise of certainty. When experience is taken as the origin of knowledge, the individual subject's perception becomes the bedrock of evidence on which explanation is built at the expense of inquiry into subject formation. Joan Scott argues that reliance on experience precludes critical examination of the workings of the ideological system itself, its categories of representation (such as man, woman, homosexual, heterosexual), its premises about what these categories mean and how they operate, and of its notions of subjects, origins, and cause. Instead "experience" reproduces its terms: it does not allow us to see that it is not the individuals who have experience, but subjects who are constituted through experience (1991, p. 777). By taking experience to be a given, and ignoring how discourse and history structure one's experiences, the status quo-the same social order that maintains the privilege of the modest witness - is left unexamined.

Because knowers are understood to be collaborative agents, whose epistemic projects are shaped by, and evaluated within, the communities where their knowledge-producing practices occur, standards of evidence are by no means "self-announcing", but rather historically relative, dynamic, and of our own making (Nelson, 1993a). While experience can remain central to our evidential claims, it must be understood to be inherently social, for we experience the world through the lens of our projects, categories, theories, and standards. Therefore, what constitutes evidence for specific claims or theories includes not only experience, but also the knowledge and standards constructed and adopted by epistemological communities (Nelson, 1993a, p. 142). Against the insistence of radical empiricists, feminists contend that science is not a value-free enterprise. Even the notion of empirical adequacy is conditioned by a set of beliefs which cannot be disentangled into "factual" and "evaluative" categories (Nelson, 1993b). The benefit of unmasking the assumptions, norms, and values at play in scientific inquiry is that we can now address the important socio-political question of which values ought to enter the scientific arena.

In sum, feminist insights tell us that rather than empirical evidence increasing certainty by factoring out the subjective features of everydayness that bias our understanding of things, the constructs of "objectivity", "universality", and "value-free" instead obscure the subjective elements that inescapably enter all forms of human inquiry. Since the evidence is by no means objective or neutral, but rather part of a social system of knowledge production, many feminist epistemologists recommend social models of scientific practice. This model entails recognising our background assumptions as playing a constitutive (and not a biasing) role in knowledge acquisition and evaluation (Longino, 1990). Scientific inquiry cannot be value-free, as traditional empiricists required, for cultural and social values make knowledge possible. These values must, of course, be subject to examination and 
critique, ideally by those from outside the community who do not share those cultural assumptions. Thus the evaluation of scientific beliefs becomes more rigorous: in addition to demonstrating empirical adequacy, scientific beliefs must be subject to public scientific inquiry, where the background assumptions motivating the investigation are explicitly recognized and therefore subject to the same critical scrutiny to which "good empiricists" (Feyerabend, 1998) subject their knowledge claims. This public activity not only raises the standards of theoretical adequacy, but also better mediates the knowledge/power interplay in scientific investigation. Once we recognise that an uninterrogated conception of empirical adequacy is not sufficient to act as a criterion of theory choice, we can turn to the question of what epistemological virtues we want our theories to additionally display. A feminist philosophy of science is explicitly political, as science is recognised to be a vehicle for feminism's emancipatory programme.

\section{Feminist implications for EBM}

Against feminist misgivings about so-called objectivity, rationality, and value-neutrality, EBM proposes to introduce rational order into the deliberative processes of healthcare decision-making. The epistemic concerns of feminist scientists and philosophers are accompanied by a feminist commitment to improving the lives of women. Feminist critiques of science are driven by a deep concern that the abstractions made in the names of scientific objectivity, generalisability, and predictability harm women. These tendencies appear to resurface in the practice of EBM.

EBM offers the promise of consistent and impartial evidence about the benefits and harms of treatments due to the transparent use of highquality primary research in systematic reviews and meta-analyses. These results are then applied in equally transparent processes to make clinical decisions (Rogers, 2004a). Feminist insight reveals that the practices of EBM are marked by potential or actual gender bias, which has led at least one critic to argue that EBM is bad for women's health (Rogers, 2004b). Despite the idealistic suggestion that evidence-based methods can improve women's health by making available more high-quality data regarding the efficacy of different treatments, thus leading to more informed treatment choices by and for women, EBM is in fact "superimposed upon current medical practice, repeating and reinforcing existing biases against women, both in research and in treatment" (Rogers, 2004b, p. 54). The shortcomings of biomedicine for properly addressing women's health needs, as articulated by feminist scholars and allies of the women's health movement over the past few decades, are not corrected by evidence-based medical practice.

Because evidence-based clinical decision-making, policy determinations, and the formulation of clinical guidelines rely upon existing clinical research, the movement reflects any gaps or biases that currently exist in medical research. Women's health research has been marked by a sexist research agenda that over-focuses on women's reproductiverelated issues (fertility, menstruation, menopause, and breast and gynecological cancers) while failing to properly investigate gender dimensions of other health problems that appear to have sex-differentiated causes, incidences, responses to treatment, and prognoses due to a combination of biological factors, social conditions, and social processes (Rogers, 2004b). Some examples include HIV/ AIDS, coronary heart disease, depression, and tuberculosis.

Gender bias also arises in the performance of research, where women have been grossly underrepresented as subjects in clinical trials (Dresser, 1992; Merton, 1993). ${ }^{3}$ This exclusion has been justified on the grounds of the need for homogenous subject populations, the fear of harms to pregnant women and offspring, the alleged difficulties accounting for women's hormonal fluctuations in data analysis, and the purported difficulties recruiting women (Dresser, 1992). Critics insist, however, that biological differences between men and women are significant enough that research evidence is often not relevant to women and therefore the use of medical technologies on and by female patients is dangerous. Despite robust criticism, the bias towards male participants in research trials remains. In the US, $85 \%$ of research participants are male; this rises to $95 \%$ in Canada (Sherr, 2000).

The fact that certain areas of women's health are underresearched, others are overresearched, and other areas of health research lack evidence relevant to women suggests that the evidence that serves as the basis for EBM may not be helpful for women. EBM is implicated for the past mistakes of medicine

\footnotetext{
${ }^{3}$ This is especially the case for women of colour and elderly women.
} 
because it presents much of this evidence as authoritative and even arguably reifies much of the thinking and methods that allowed for these egregious gaps in research to occur in the first place.

Feminist researchers have found bias against women not only in the production of the research that informs EBM, but also in the purportedly fair methods used to analyse and synthesise the evidence (Rogers, 2000b). A common critique of EBM's pregraded evidence hierarchies is that they do not acknowledge that research methods must be tailored to the question at hand, and that different questions gather best evidence from different research designs. Leaving aside the gendering of the quantitative vs. qualitative debates in the social sciences - with the former being regarded as "masculine" and the latter as "feminine" (Oakley, 2000) - qualitative methods have been favoured by many feminist researchers for allowing the voices of women to be heard in describing problems and in finding solutions. The endorsement of an evidence hierarchy that discounts evidence from qualitative research has implications for women's health insofar as health interventions that recognise the social and political context contributing to women's poor health have consistently proven to be more effective in improving health outcomes. EBM methodology in fact supports a reductionist model of health and disease that is not amenable to the crucial social and political determinants of women's health.

\section{Phenomenology of science and medicine}

Phenomenological approaches to science and medicine further challenge notions of evidence in EBM by questioning why relevant evidence is assumed to come primarily from clinical trials and other "objective" measures. They argue instead that the patient's self-understanding and experience of illness ${ }^{4}$ also offers a legitimate source of relevant medical knowledge. This theoretical approach is grounded in the philosophy of Edmund Husserl and his followers who questioned the philosophical completeness of natural sciences. They argued that

\footnotetext{
${ }^{4}$ The emphasis on the patient's experience of illness in medical phenomenology may seem, at first, to be at odds with feminist epistemology, where the evidence of experience is suspect. Feminists speak to supposedly universal sensory experience, which is shared by ideal observers and grounds empiricist knowledge claims, however, while phenomenologists focus on the very subjective experience of illness (or the illness narrative).
}

Cartesian dualism, which split the world into minds and bodies, the spiritual and the physical, was erroneous and created a truncated body of science that exhibited impressive technological ability to control nature, but could not address questions of human self-understanding. This led to a "crisis of meaning", which Husserl (1970) attributes to the failure of positivist natural science.

The biomedical model is charged with suffering from similar problems, as the technological abilities of modern medicine fail to address the existentiality of illness. Self-proclaimed "medical humanists" like Reiser (1978), Reiser and Rosen (1984), who lament the lost "art" of medicine, regard the well-documented increase in patient dissatisfaction (despite the amazing technological advances) as a similar crisis. The rising popularity of alternative medicine can be understood to be part of that backlash, as patients increasingly seek out unorthodox practices despite the impressive technological success of the orthodoxy. The biomedical model is grounded in the natural sciences, and medical practice consists of the practical application of these sciences to human illness and health (Schwartz \& Wiggins, 1985, p. 333). However, with the unity, predictive power, and exactitude of scientific medicine comes the neglect of those components of human distress that elude description in natural scientific nomenclature (Schwartz \& Wiggins, 1985, p. 332). It is demonstrated in the illness narratives of Toombs (1993) and Sacks (1984) that these nonsomatic components of human life that are typically disregarded as "subjective" features of illness stubbornly remain crucial to the experience of illness and to recovery.

By taking seriously questions about the world as experienced rather than scientifically described, phenomenologists seek to reunite science with life experience and to explore the relationship between the abstract world of the sciences and the concrete world of human consciousness. Toombs (1993) argues that as embodied beings, we experience life in and through the body both before and after we develop cognitive and symbolic structures for mapping experience and meaning. Phenomenologists typically speak of "embodiment" instead of "the body" to deemphasise the physical body and the assumed subject-object split that comes with anatomical description. They instead aim to create an understanding of our bodies in their experiential "givenness".

From this emphasis on the "lifeworld" rather than the scientific organisation of the world, a 
different account of illness ensues. When the body is no longer thought of as an anatomical entity, but rather as the source of our experiences, illness becomes a way of "being-in-the-world" that is best described as a sense of disorder, a loss of control, of "things not being right in the world". This embodied understanding of illness resists medical classification as these categories lack its existential qualities. In fact, illness may not even be localised to any one place. Scarry (1985) has forcefully described in The Body in Pain: The Making and Unmaking of the World (1985) that pain obliges a loss of the taken-for-grantedness of our bodies, and illness can be understood as, similarly, the loss of the "athandedness" or "everydayness" (Heidegger, 1996) of things. Toombs' (1993) philosophical reflections on living with MS lead her to conclude that health is not experienced as the absence of disease, but rather as a state of unselfconscious being that illness shatters. Illness is a problem of embodiment, as the usual effortless and unselfconscious unity of the body and the self is disrupted, making one pay explicit attention to the body as suddenly problematic (and separate or alien from the self).

Toombs (1993) examines the different ways that physicians and patients approach and understand illness and encourages physicians to try to understand what illness means to the patient. She advises that rather than trying to understand disease as a breakdown of the objectified body-machine, the physician must try to approach illness as a disturbance in the patient's ability to relate to and function in the world, as it is one's embodiment, one's capability of interacting with the world, that is damaged in the event of illness.

Such an approach to medical practice would entail a radically different understanding of evidence, and probably lead to a new scientific method. Once the patient and not the disease exemplar becomes the subject of examination and treatment, the personal anecdotes, life circumstances, and other subjective features of the patient's circumstances become crucial parts of the diagnosis (Greenhalgh \& Hurwitz, 1998). Diagnosis would not be tailored to medical categorisation, as the goal of treatment would not be centred so much on the elimination of disease, but rather the reintegration of the patient into the lifeworld. ${ }^{5}$

\footnotetext{
${ }^{5}$ This is not to say that the elimination of disease would not be an important feature of treatment, but it certainly would not be regarded as more important than, say, rehabilitation. To borrow
}

\section{Phenomenological implications for evidence-based medicine}

Reflecting on how the popular idea of "patientcentred care" remains largely unrealized in clinical practice, Van Weel and Knottneurus (1999) note that while physicians are encouraged to make diagnoses in physical, psychological, and social terms, "the EBM that is currently promoted either restricts itself to physical evidence alone, or casts such evidence at the top of a hierarchy that tends to devalue any evidence "lower down"'. The hierarchy of evidence promotes a certain scientistic accounting of the goals of medicine, which, the worry goes, is incommensurable with the proposed reorientation of medical practice toward the patient's search for meaning in the illness experience. The bridging of scientistic "measure" and existential "meaning" has received some attention in the critical EBM literature (see, for example, Buetow, 2002; Djulbegovic, Morris, \& Lyman, 2000; Upshur et al., 2001) with the general consensus that we need an "integrated" model of evidence that properly reflects modern health care's constitution by diverse academic traditions - including the humanities, social sciences, and the pure and applied sciencesthat rely on equally diverse notions of evidence (Upshur et al., 2001, p. 91).

While EBM values evidence that is statistical in nature and general in its application, and therefore places quantitative data derived through the application of recognised study designs at the top of its pre-graded hierarchies of evidence, the phenomenological approaches rooted in hermeneutics, ethnography, sociology, and anthropology, regard evidence as primarily narrative, subjective, and historical in nature. Unlike the impersonal and generalisable measures undertaken in EBM, this conception of evidence is illustrated in case histories, clinical encounters, and qualitative studies such as in-depth interviews and focus groups (Upshur et al., 2001, p. 94).

The features of the medical encounter and the illness experience emphasised by medical phenomenologists and proponents of a more "humane" medicine suggest the need to reconsider what constitutes the goals of medicine (Cassell, 1982; Toombs, 1995; 1993) and flip EBM's hierarchy of

\footnotetext{
(footnote continued)

a slightly overused expression, this model emphasises care instead of cure.
} 
evidence on its head. The quantitative measures and generalisations that come out of controlled trials and biostatistical analysis are not conducive to the questions of meaning that medical phenomenology wants to address and make central to medicine.

\section{The politics of evidence}

Because EBM is largely an effort to manage the unruly social world in which medicine is practiced via objective scientific procedure, the movement appears to be the latest expression of "scientism", modernity's rationalist dream that science can produce the knowledge required to emancipate us from scarcity, ignorance, and error. However, such efforts tend to disguise political interests in the authority of so-called "scientific evidence". The configuration of policy considerations and clinical standards into questions of evidence conveniently transform normative questions into technical ones. Political issues are not resolved, however, but merely disguised in technocratic consideration and language. Thus the goals of medicine and other normative considerations lie just below the surface of these evidentiary questions, and evidence becomes an instrument of, rather than a substitute for, politics (Belkin, 1997; Rodwin, 2001).

\section{In conclusion}

The basic tenets of EBM, it seems, rest on the unquestioned authority of scientific evidence, a position that is now out of step with current postpositivistic thinking. Nelson (1993a) has argued that any call for evidence (or a claim to lack it) relies on a specific conception of evidence. The conception of evidence used in EBM has been demonstrated to be problematic by post-positivists, feminist epistemologists and medical phenomenologists.

Relying on "the facts" or "the evidence" to adjudicate between competing clinical practices or scientific beliefs assumes that the evaluative standards of EBM are transparent, neutral, objective, and universal. The numerous accounts of scientific knowledge as "situated knowledges" (Haraway, 1988) offered by post-positivist, feminist, and phenomenological thinkers suggest that this understanding of evidence is far too simple and no longer a tenable position in science studies. Furthermore, against the position that modern science stands out as the only objective method of knowledge-gathering, feminist epistemologists and phenomenologists demonstrate the biases implicit in the modern scientific worldview and offer ways of conceiving evidence differently.

While the assertions of EBM may seem common sense, we must remember that they have been stripped of the social context of medical practice. Just as feminist epistemologists have demonstrated how this alleged value-neutrality distorts scientific practice, the same concerns arise in medicine. In an age where the institutional power of medicine is suspect (for all the reasons offered by Foucault (1990)), a model that represents biomedicine's power as disinterested (or merely "scientific") should give pause for thought. Denny (1999) reads EBM as a discourse that problematically resists contemporary challenges to established medical authority. While EBM may appear to question the authority of individual physicians, it actually reinforces it through the regulation of doctor's authority/ knowledge. Furthermore, it does not question the institutional authority of medicine itself to the rest of society, the way healthcare dollars are allocated for the necessary clinical research, and what role the pharmaceutical industry plays in setting the research agenda. It has been argued that the separation of the technical and the political is an instructive mark of modernity (Haraway, 1996; Habermas, 1989). This removal of normative content from the ideological apparatuses has the dangerous effect of depoliticising the organisation of social life and therefore justifying the institutions by rendering them functional within a system of supposedly technically necessary activity. By framing the problems of biomedicine as problems of (lack of) evidence exclusively, the assumptions, methods, and practices of scientific medicine go unquestioned. While evidenced-based approaches can improve de rigueur medical practice, "evidence-based" should not be understood to be synonymous with "best practice" in all relevant respects.

A lesson learned from the philosophy of science is that evidence is not self-apparent or "given" when gathered from even the most idealised and controlled observational setting. The critiques launched against positivist philosophy by feminist and phenomenological epistemologies of science contest the seemingly unproblematic nature of "evidence" that underlies EBM by emphasising different features of the social nature of science. The appeal to the authority of evidence that characterises evidence-based practices does not increase objectivity but rather obscures the subjective elements that 
inescapably enter all forms of human inquiry. Abstracted from the social context of medicine, EBM seems common sense and the connections between power and knowledge are obscured.

\section{Acknowledgements}

An earlier version of this paper was written as part of my comprehensive exams in preparation for my dissertation project. Thanks to my dissertation committee: Jim Lindemann Nelson, Judy Andre, Marilyn Frye, Fred Gifford, and Lisa Schwartzman. Also, to my audience and co-panelists at the presentation of a later draft at the 2004 meeting of the American Society for Bioethics and Humanities. Finally, thanks to the editors of this volume for editorial suggestions, particularly on how to speak across disciplines.

\section{References}

Belkin, G. S. (1997). The technocratic wish: Making sense and finding power in the 'managed' medical marketplace. Journal of Health Politics, Policy and Law, 22, 509-532.

Bordo, S. (1987). The flight to objectivity: Essays on cartesianism and culture. Albany: SUNY Press.

Buetow, S. A. (2002). Beyond evidence-based medicine: Bridgebuilding a medicine of meaning. Journal of Evaluation in Clinical Practice, 8, 103-108.

Buetow, S. A., \& Keneally, T. (2000). Evidence-based medicine: The need for a new definition. Journal of Evaluation in Clinical Practice, 6, 85-92.

Candelise, L., Aritzu, E., Ciccone, A., Ricci, S., \& Warlaw, J. (1995). Randomised controlled trial of streptokinase, aspirin, and combination of both in treatment of acute ischemic stroke. Lancet, 346, 1509-1514.

Cassell, E. J. (1982). The nature of suffering and the goals of medicine. New England Journal of Medicine, 306, 639-645.

Code, L. (1991). What can she know? Feminist theory and the construction of knowledge. Ithaca, NY: Cornell University Press.

Code, L. (1993). Taking subjectivity into account. In L. Alcoff, \& E. Potter (Eds.), Feminist epistemologies (pp. 15-48). New York: Routledge.

Davidoff, F., Haynes, B., Sackett, D., \& Smith, R. (1995). Evidence-based medicine. British Medical Journal, 310, 1085-1086.

Denny, K. (1999). Evidence-based medicine and medical authority. Journal of Medical Humanities, 20(4), 247-263.

Djulbegovic, B., Morris, L., \& Lyman, G. (2000). Evidentiary challenges to evidence-based medicine. Journal of Evaluation in Clinical Practice, 6(2), 99-109.

Dresser, R. (1992). Wanted: Single, white male for medical research. Hastings Center Report, 22, 24-29.

Duhem, P. (1982). The aim and structure of physical theory. Princeton: Princeton University Books.
Fausto-Sterling, A. (1989). Life in the XY corral. Women's Studies International Forum, 12(3), 319-331.

Fausto-Sterling, A. (1992). Myths of gender: Biological theories about women and men. New York: Basic Books.

Feyerabend, P. (1978). Against method. London: Verso.

Feyerabend, P. (1998). How to be a good empiricist - A plea for tolerance in matters epistemological. In M. Curd, \& J. A. Cover (Eds.), Philosophy of science: The central issues (pp. 922-949). New York: Norton.

Foucault, M. (1990). The history of sexuality: An introduction (Vol. 1). New York: Vintage Books.

Goldenberg, M. J. (2005). Evidence based ethics? On evidence based practice and the "empirical turn" from normative bioethics. BMC Medical Ethics, 6, 11.

Goodman, K. W. (2003). Ethics and evidence-based medicine: Fallibility and responsibility in clinical science. Cambridge: Cambridge University Press.

Greenhalgh, T., \& Hurwitz, B. (Eds.). (1998). Narrative based medicine: Dialogue and discourse in clinical practice. London: BMJ Publishing Group.

Grimshaw, J. (2004). So what has the Cochrane Collaboration ever done for us? A report card on the first 10 years. Canadian Medical Association Journal, 171, 747.

Guyatt, G., Cairns, J., Churchill, D., et al. (1992). Evidencebased medicine. Journal of the American Medical Association, 268, 2420-2425.

Habermas, J. (1989). Technology and science as ideology. In S. Seidman (Ed.), Jurgen Habermas on society and politics: $A$ reader (pp. 237-265). Boston: Beacon Press.

Hanson, N. R. (1958). Patterns of discovery. Cambridge: Cambridge University Press.

Haraway, D. (1988). Situated knowledges: The science question in feminism and the privilege of partial perspective. Feminist Studies, 14(3), 575-599.

Haraway, D. (1989). Primate visions: Gender, race, and nature in the world of modern science. London: Routledge.

Haraway, D. (1991). Simians, cyborgs, and women: The reinvention of nature. New York: Routledge.

Haraway, D. (1996). Modest witness: Feminist diffractions in science studies. In P. Galison, \& D. Stump (Eds.), The disunity of science: Boundaries, contexts, and power (pp. 428-442). Stanford: Stanford University Press.

Harding, S. (1986). The science question in feminism. Ithaca, NY: Cornell University Press.

Heidegger, M. (1996). Being and time. Albany, NY: SUNY Press (translated by J. Stambaugh).

Horton, R. (1995). MAST-I: Agreeing to disagree. Lancet, 346, 1504.

Hubbard, R., \& Lowe, M. (Eds.). (1979). Genes and gender. New York: Gordian Press.

Hume, D. (1977). In E. Steinberg (Ed.), An enquiry concerning human understanding. Indianapolis: Hackett.

Hume, D. (2000). In D. F. Norton, \& M. J. Norton (Eds.), $A$ treatise of human nature. Oxford: Oxford University Press.

Husserl, E. (1970). The crisis of European sciences and transcendental phenomenology. Evanston, IL: Northwestern University Press (translated by D. Carr).

Husserl, E. (1982). Ideas pertaining to a pure phenomenology and a phenomenological philosophy: First book: General introduction to a pure phenomenology.The Hague: Nijoff (translated by F. Kersten).

Keller, E. F. (1985). Reflections on gender and science. New Haven, CT: Yale University Press. 
Kuhn, T. (1970). Reflections on my critics. In I. Lakatos, \& A. Margraves (Eds.), Criticisms and the growth of knowledge (pp. 231-278). Cambridge: Cambridge University Press.

Kuhn, T. (1996) (3rd ed). The structure of scientific revolutions. Chicago: University of Chicago Press.

Longino, H. (1990). Science as social knowledge: Values and objectivity in scientific inquiry. Princeton: Princeton University Press.

Merton, V. (1993). The exclusion of pregnant, pregnable, and once-pregnable people (AKA women) from biomedical research. American Journal of Law and Medicine, 19, 369-451.

Nelson, L. H. (1993a). Epistemological communities. In L. Alcoff, \& E. Potter (Eds.), Feminist epistemologies (pp. 121-160). New York: Routledge.

Nelson, L. H. (1993b). A question of evidence. Hypatia, 8(2), 172-190.

Oakley, A. (2000). Experiments in knowing: Gender and method in the social sciences. Oxford: Polity Press.

Quine, W. V. (1960). Word and object. Cambridge, MA: MIT Press.

Reiser, D., \& Rosen, D. (1984). Medicine as a human experience. Baltimore: University Park Press.

Reiser, S. J. (1978). Medicine and the reign of technology. New York: Cambridge University Press.

Rodwin, M. (2001). The politics of evidence-based medicine. Journal of Health Politics, Policy, and Law, 26, 439-445.

Rogers, W. A. (2004a). Does evidence-based medicine offer fair benefits for all? Ethics Journal of the American Medical Association, 6(12) www.ama-assn.org/ama/pub/category/14295.html.

Rogers, W. A. (2004b). Evidence-based medicine and women: Do the principles and practice of EBM further women's health? Bioethics, 18(1), 50-70.
Sackett, D., Rosenberg, W., Gray, J. A. M., Haynes, B., \& Richardson, W. S. (1996). Evidence-based medicine: What it is and what it isn't. British Medical Journal, 312, 71-72.

Sacks, O. (1984). A leg to stand on. New York: Summit Books.

Scarry, E. (1985). The body in pain: The making and unmaking of the world. Oxford: Oxford University Press.

Scott, J. (1991). The evidence of experience. Critical Inquiry, 178(3), 773-797.

Schwartz, M., \& Wiggins, O. (1985). Science, humanism, and the nature of medical practice: A phenomenological view. Perspectives in Biology and Medicine, 28(3), 331-361.

Shahar, E. (1997). A Popperian perspective of the terms 'evidence-based medicine'. Journal of Evaluation in Clinical Practice, 3, 109-116.

Sherr, L. (2000). Women and clinical trials. In L. Sherr, \& J. St. Laurence (Eds.), Women, health, and the mind (pp. 77-90). Chichester: Wiley.

Tanenbaum, S. J. (1993). What physicians know. New England Journal of Medicine, 329, 1268-1271.

Tognoni, G., \& Roncaglioni, M. (1995). Dissent: An alternative interpretation of MAST-I. Lancet, 346, 1515.

Toombs, S. K. (1993). The meaning of illness: A phenomenological account of the different perspectives of physician and patient. Dordrecht: Kluwer Academic Publishers.

Toombs, S. K. (1995). Chronic illness and the goals of medicine. Second Opinion, 21, 11-19.

Upshur, R. E. G., VanDenKerkhof, E. G., \& Goel, V. (2001). Meaning and measurement: An inclusive model of evidence in health care. Journal of Evaluation in Clinical Practice, 7, 91-96.

Van weel, C., \& Knottneurus, J. A. (1999). Evidence-based interventions and comprehensive treatment. Lancet, 353, 916-918. 